\title{
Ocular Morbidity Due to Monofilament Nylon Corneal Sutures
}

\author{
J. F. ACHESON and C. J. LYONS \\ London
}

The low toxicity, high elasticity and prolonged tensile strength of monofilament nylon has led to its widespread use in modern cataract surgery. ${ }^{1,2}$ With the satisfactory use of this suture in keratoplasty and the repair of corneal lacerations, ${ }^{3}$ corneal incisions for cataract extraction have become popular at many centres, including this hospital.

The clear corneal approach offers a number of potential advantages: surgery is quicker, which may facilitate more efficient use of hospital resources. Subsequent filtration procedures are simpler and their outcome is not prejudiced by the conjuctival scarring which follows limbal incisions. When interrupted sutures are used, correction of post-operative astigmatism by selective suture removal is easier. However, corneal monofilament nylon is sometimes associated with marked local tissue toxicity and is also subject to in-vivo biodegradation..$^{4-7}$ Both these mechanisms may cause significant post-operative morbidity.

We carried out a survey in the accident and emergency department of this hospital to assess the ocular morbidity caused by $10 / 0$ monofilament suture degradation after its use in clear corneal sections for cataract extraction.

\section{Materials and Methods}

Aphakic and pseudophakic patients presenting to the Accident and Emergency Department over a six-week period with symptoms resulting from loosened or broken sutures at the corneal section were studied.

The duration and nature of the symptoms, the number of sutures which were loose, broken or with a knot undone and the apparent cause of the presenting symptoms were recorded. The patients were treated by removal of the offending suture(s) under topical anaesthesia followed by topical antibiotics and occlusive dressings as appropriate.

The hospital case records were then reviewed noting the time elapsed since cataract surgery and the total number of visits to the casualty department with the same problem, not including routine clinic appointments.

\section{Results}

All forty four patients presented within seven days of onset of their symptoms. These were typically described as 'scratching, itching or pricking', watering, discharge, foreign body sensation, or non-specific discomfort. The principal causes of the presenting symptoms in the 44 patients are shown in Figure 1. The time elapsed between surgery and presentation with loose or broken sutures is shown in Figure 2.

\section{Discussion}

A total of 18 patients were recruited into the study during the only week when every suitable case was included. This represents a monthly rate of 72 , which is $14.4 \%$ of the average 500 clinic-registered patients seen each month in casualty with new presentations. The impact on medical time and on average waiting times in casualty (where, on average 5000 clinic and casualty patients are seen each month) may be significant.

Moreover, these 44 patients made an aver-

From: Moorfields Eye Hospital, City Road, London EC1V 2PD.

Correspondence to: J. F. Acheson FRCS FCOphth, Western Ophthalmic Hospital, Marylebone Road, London NW1. 


\section{OCULAR FINDINGS}

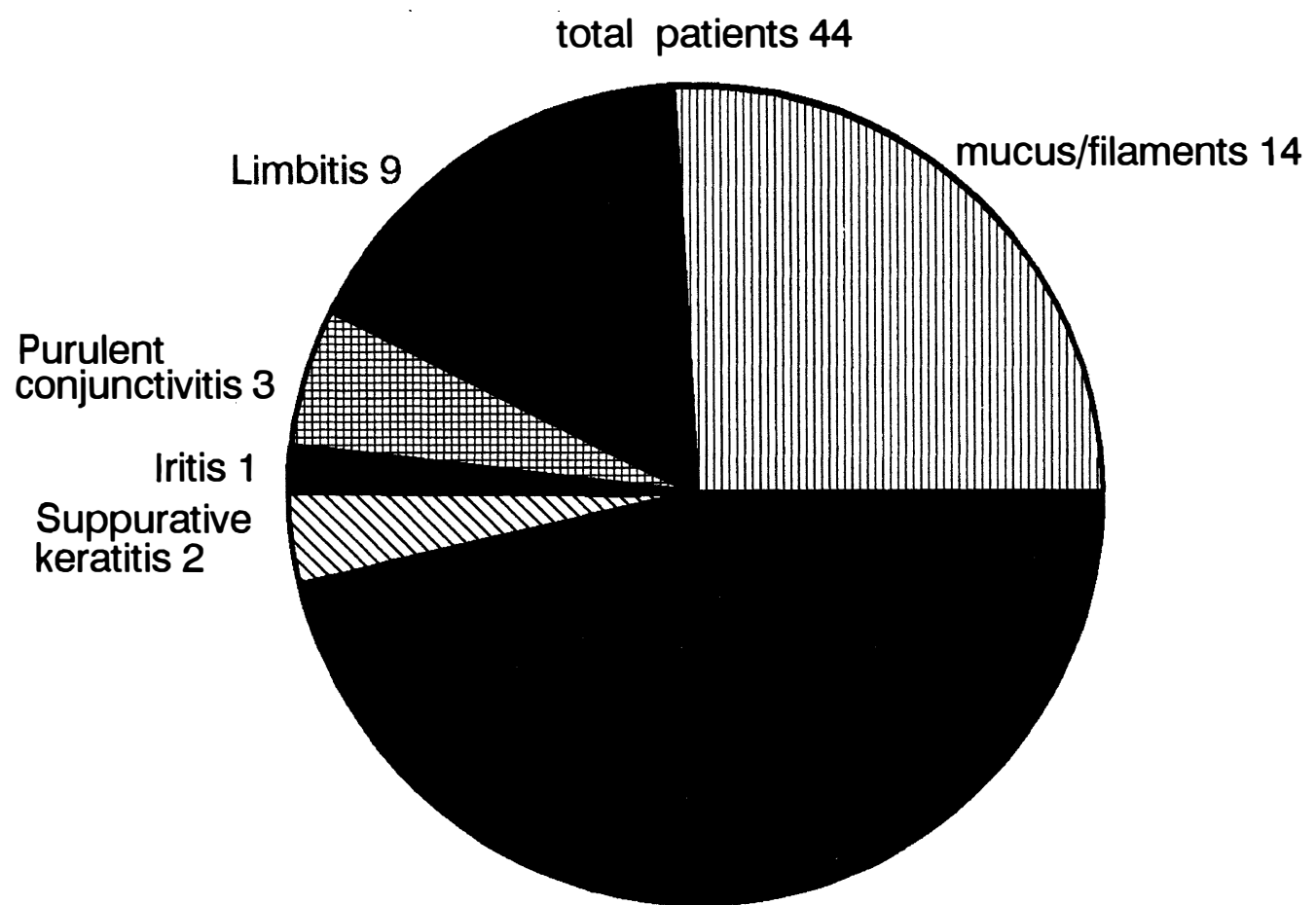

Giant papillary conjunctivitis 25

Fig. 1. Causes of symptoms arising from suture loosening or breakage.

age of two extra visits each to the casualty department on account of nylon suture loosening or breakage. This is in addition to their routine clinic visits and represents avoidable expenditure of time and money on the part of the patient.

The patients' symptoms were caused by mechanical discomfort arising either from suture breakage, or by loosening due to loss of elasticity. In addition to the expected complications of mucus accumulation under the suture, filaments, vascularisation, purulent conjunctivitis, giant papillary conjunctivitis or combinations of these conditions, two patients presented with suppurative keratitis which required treatment with intensive topical antibiotics (Figs 3-7). With the important exception of suppurative keratitis this clinical spectrum has been described by Nikankari ${ }^{8}$ and by Shaninian ${ }^{y}$ as a result of unrotated intact nylon suture ends, but not as a result of loosening and breakage of properly rotated sutures.
The bimodal distribution of presentation times after surgery reflects two distinct biophysical processes. The first group present within the first three to six months following surgery. Their symptoms are caused by suture loosening with mucus accumulation and the recruitment of an inflammatory response. The most likely cause of loosening in the majority of cases presenting within six weeks is uneven suture tension at the time of surgery. In two patients a diffuse limbitis with scleral infiltrates at multiple suture sites was observed suggesting a 'cheesewiring' phenomenon (Fig 3). This appeared to be the result of an acute inflammatory response causing collagen destruction and allowing suture loosening. Balgest and colleagues ${ }^{4}$ have recently reported 10 eyes with limbal incisions closed with continuous 10.0 nylon which developed a similar inflammatory reaction one to six weeks after uncomplicated extracapsular cataract surgery. A toxic or 'allergic' cause was postulated related either 


\section{PRESENTATION TO EYE CASUALTY MONTHS POST-SURGERY}
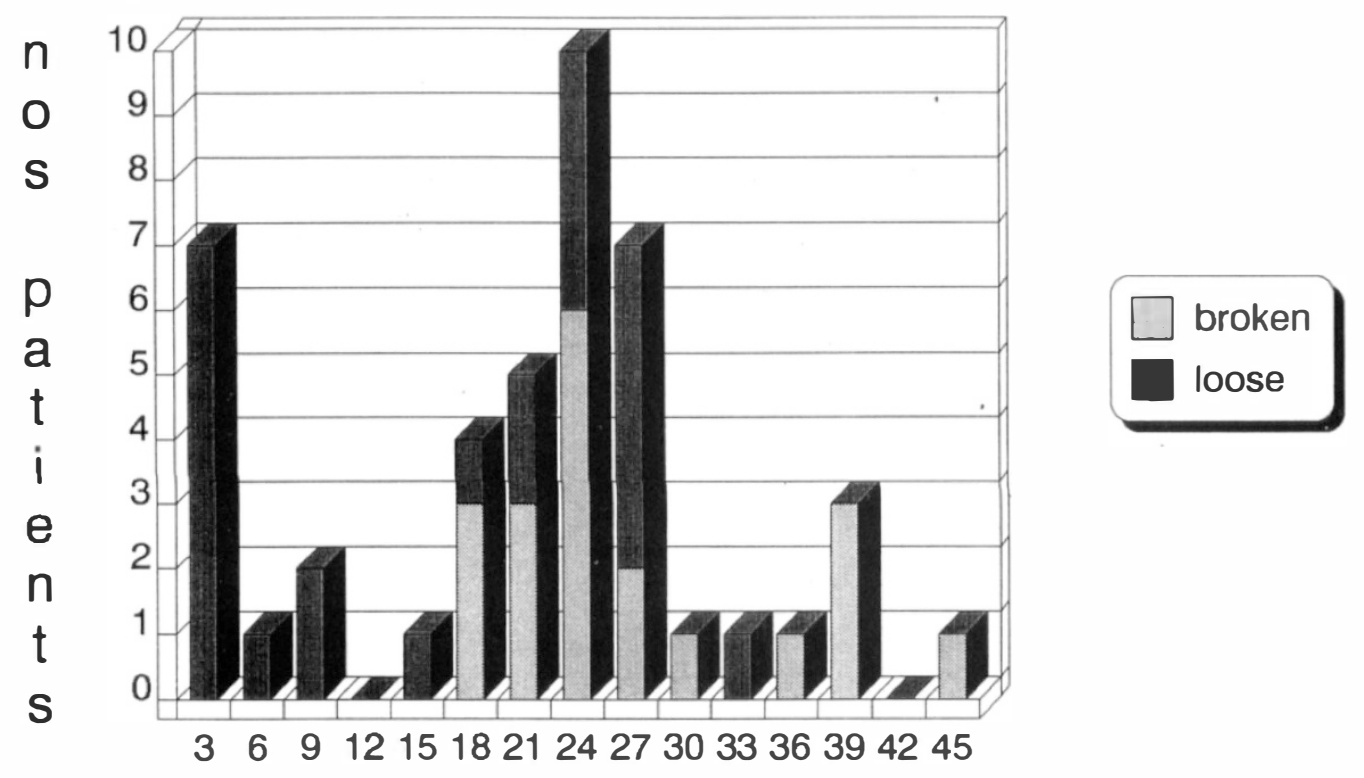

\section{months post surgery}

Fig. 2. Time elapsed between surgery and presentation with loose or broken sutures.

to the nylon itself or to the black logwood dye added during manufacture to give its colour.

The second group of patients presented with loose or broken sutures 12 months or more after surgery. In this group, the underlying process appears to be biodegredation of the suture material. This is an inherent property of the in vivo use of monofilament. ${ }^{5,6}$

Commercial monofilament nylons differ chemically with varying compositions of nylon 6 and nylon 6,6 and physically with various techniques of sterilisation and monofilament stretching. In-vivo studies ${ }^{5}$ have shown that nylon fibres are subject to enzymatic degradation by the second week after surgery, whereas polypropylene (Prolene) shows no such degradation during a 210 day period. Breaking strength changes in monofilament nylon after implantation in the rat sub-cutis suggest that both nylon 6 and nylon 6,6 lose approximately $20 \%$ of their tensile strength per year.

Monofilament nylon is formed from long molecular chains joined by amide linkages between carboxyl and amide monomers.
These amide linkages are subject to in-vivo hydrolysis ${ }^{2,5}$ leading to biodegradation (Figs 8 \& 9) and consequent loss of substance and tensile strength. Hydrolysis of polyamide sutures is thought to be mediated by lysosomal enzymes and varies according to the tissue implanted. Hayasaka and others ${ }^{7}$ have shown that uveal tissue causes a much greater degree of erosion that cornea or sclera. Nondegradable polypropylene and polyester (mersilene) (Fig 4) are the preferred sutures for iris fixation for this reason. ${ }^{1}$ The rate of biodegradation may also be proportional to the amount of tension to which the suture is subjected. ${ }^{10}$

\section{Conclusions}

This study indicates a large number of extra visits to the hospital by post-operative cataract patients for the management of suturerelated problems. Clearly this represents inconvenience and expense to patients and an avoidable demand upon medical time. Certain modifications to the current management of cataract patients can be suggested: 


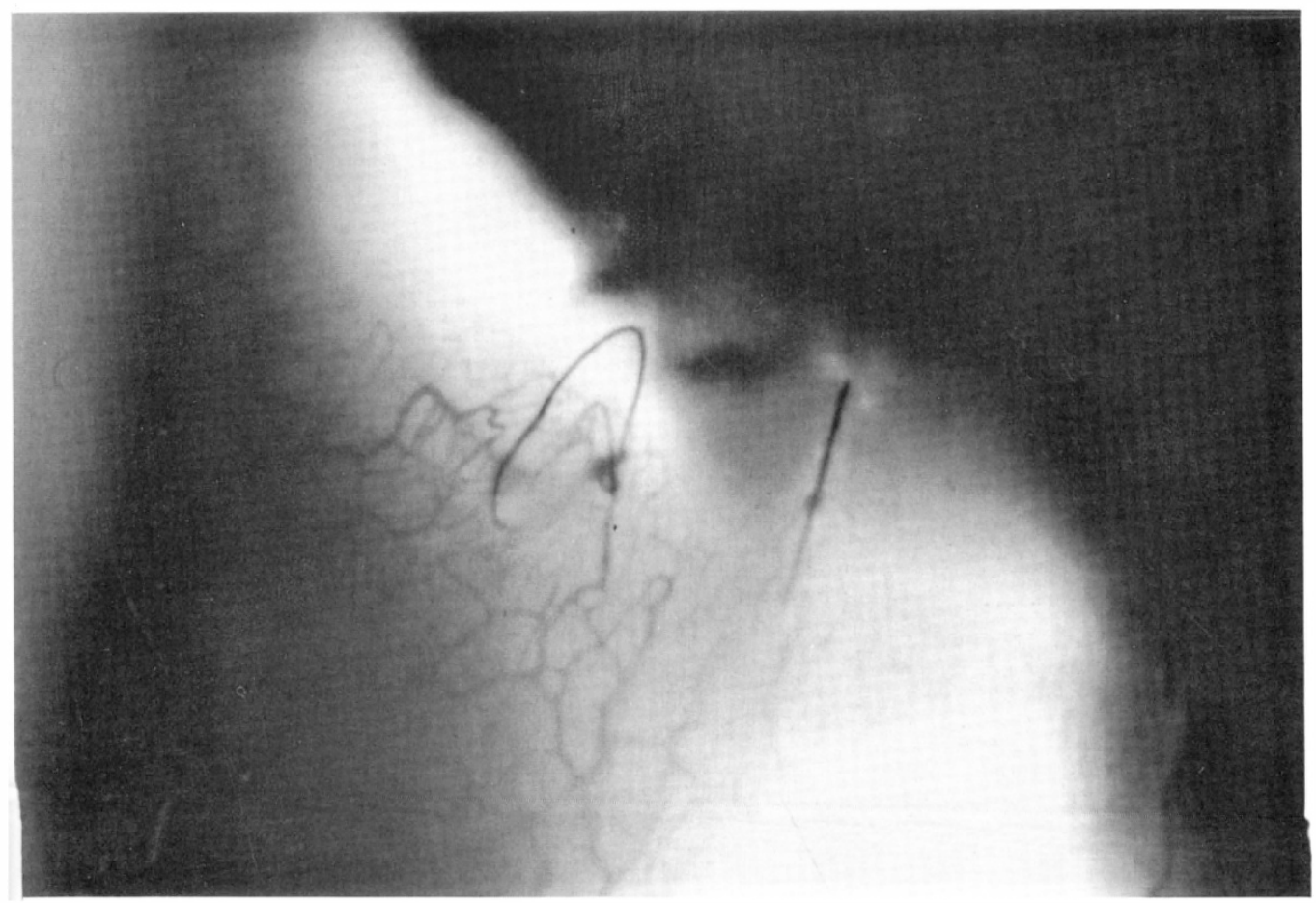

Fig. 3. Early loosening due to uneven tension at surgery.

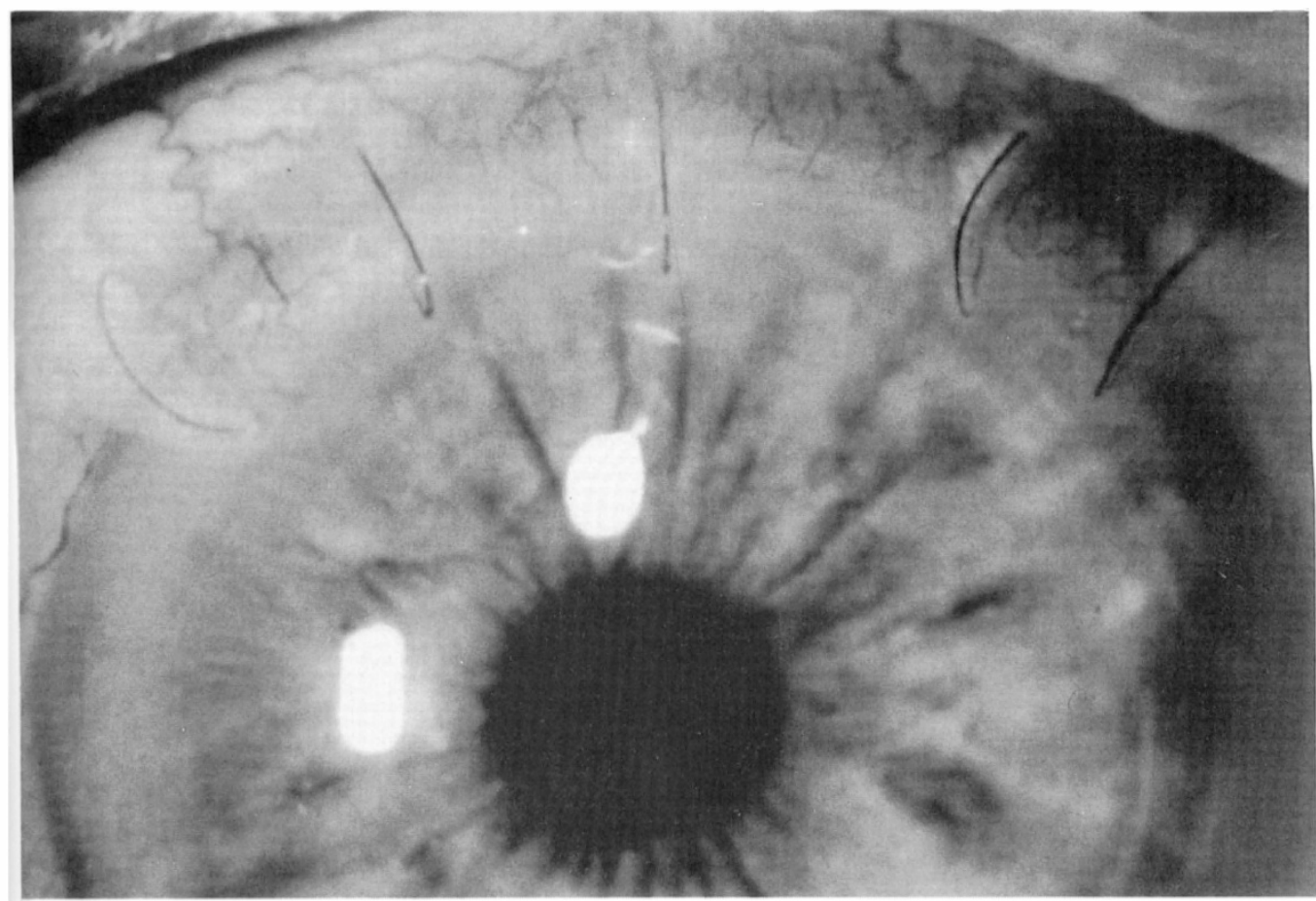

Fig. 4. Early loosening due to inflammatory limbal response and 'cheesewirting'. 


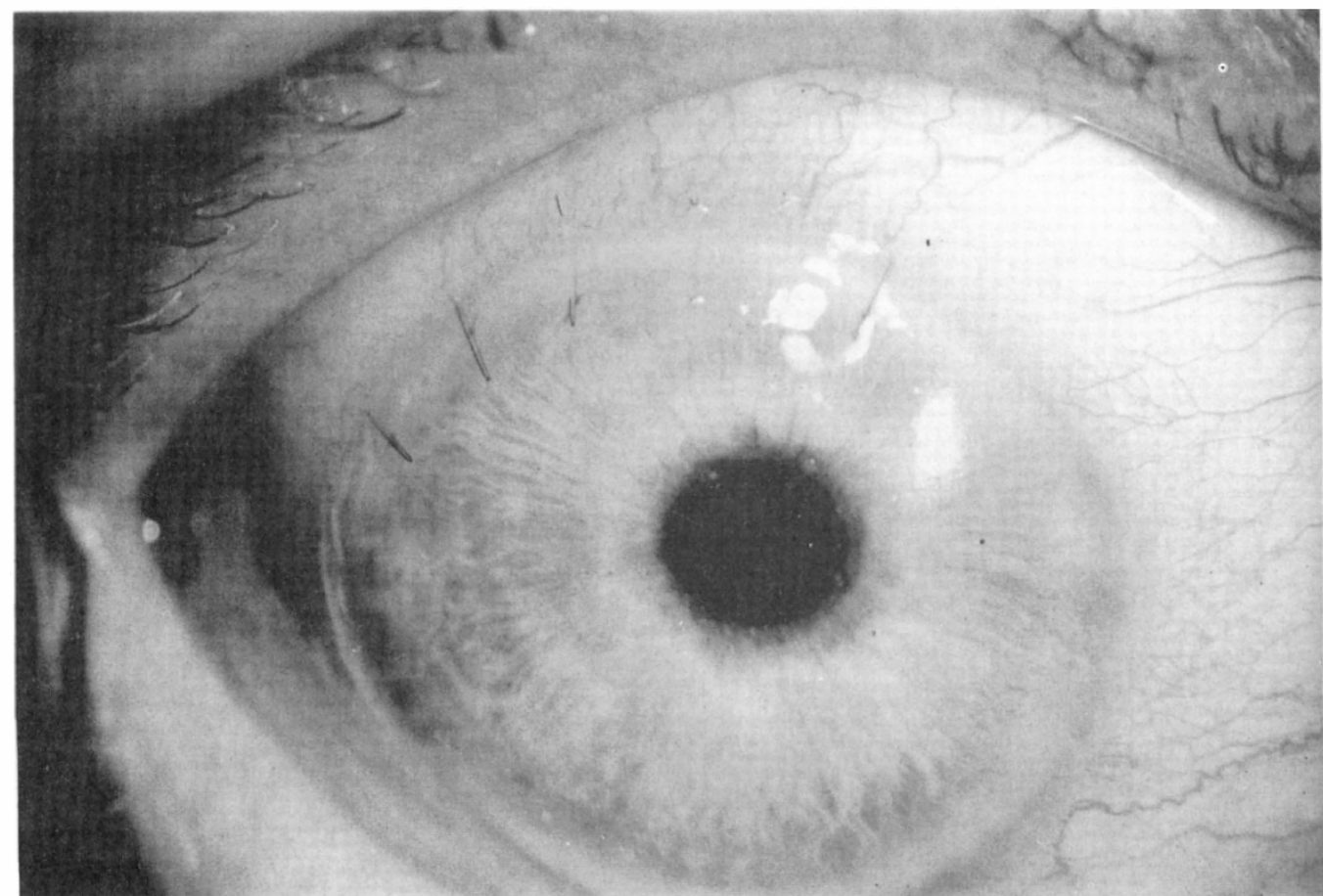

Fig. 5. Filamentary keratitis associated with suture breakage.

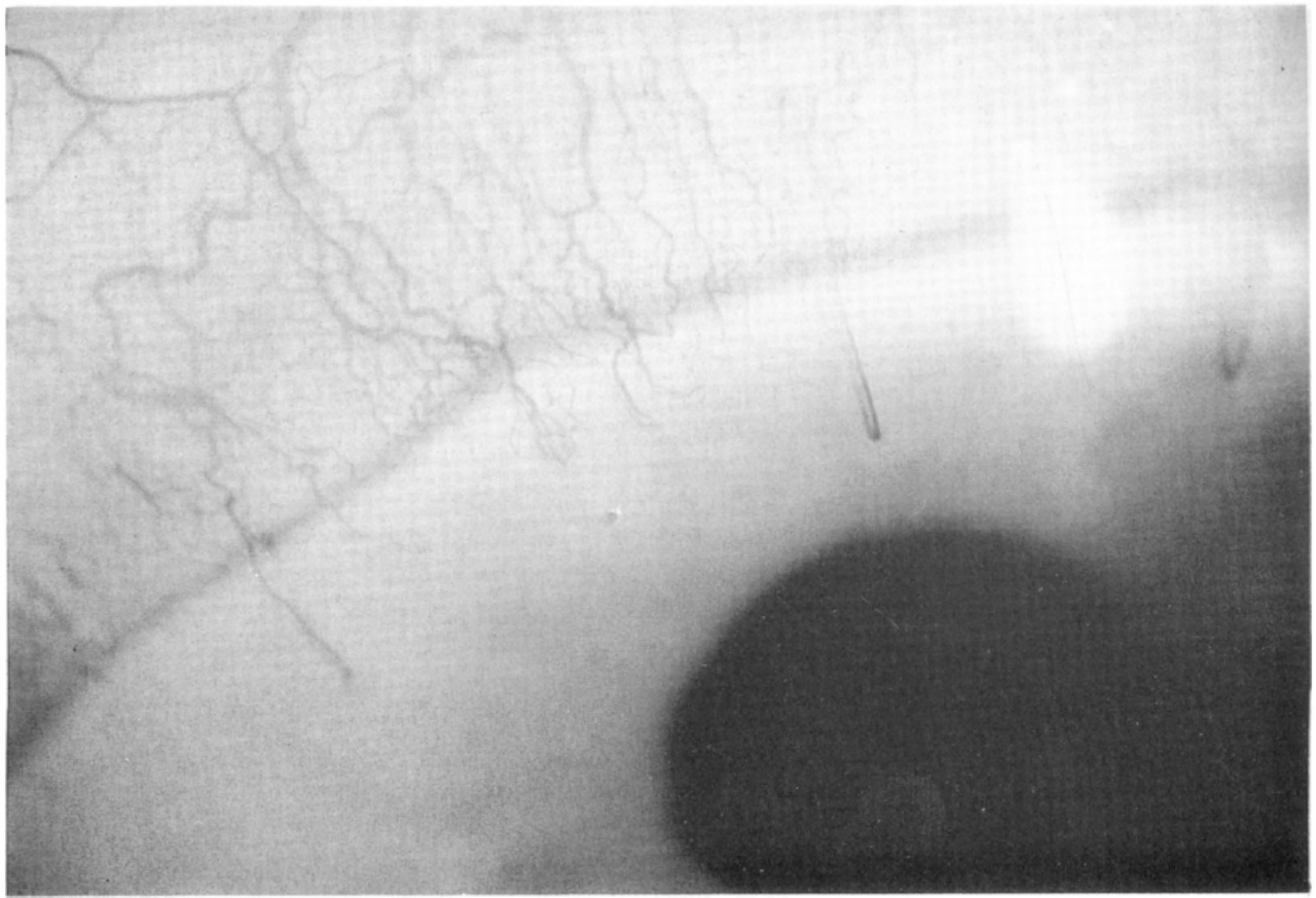

Fig. 6. Peripheral superficial corneal vascularisation associated with suture breakage. 


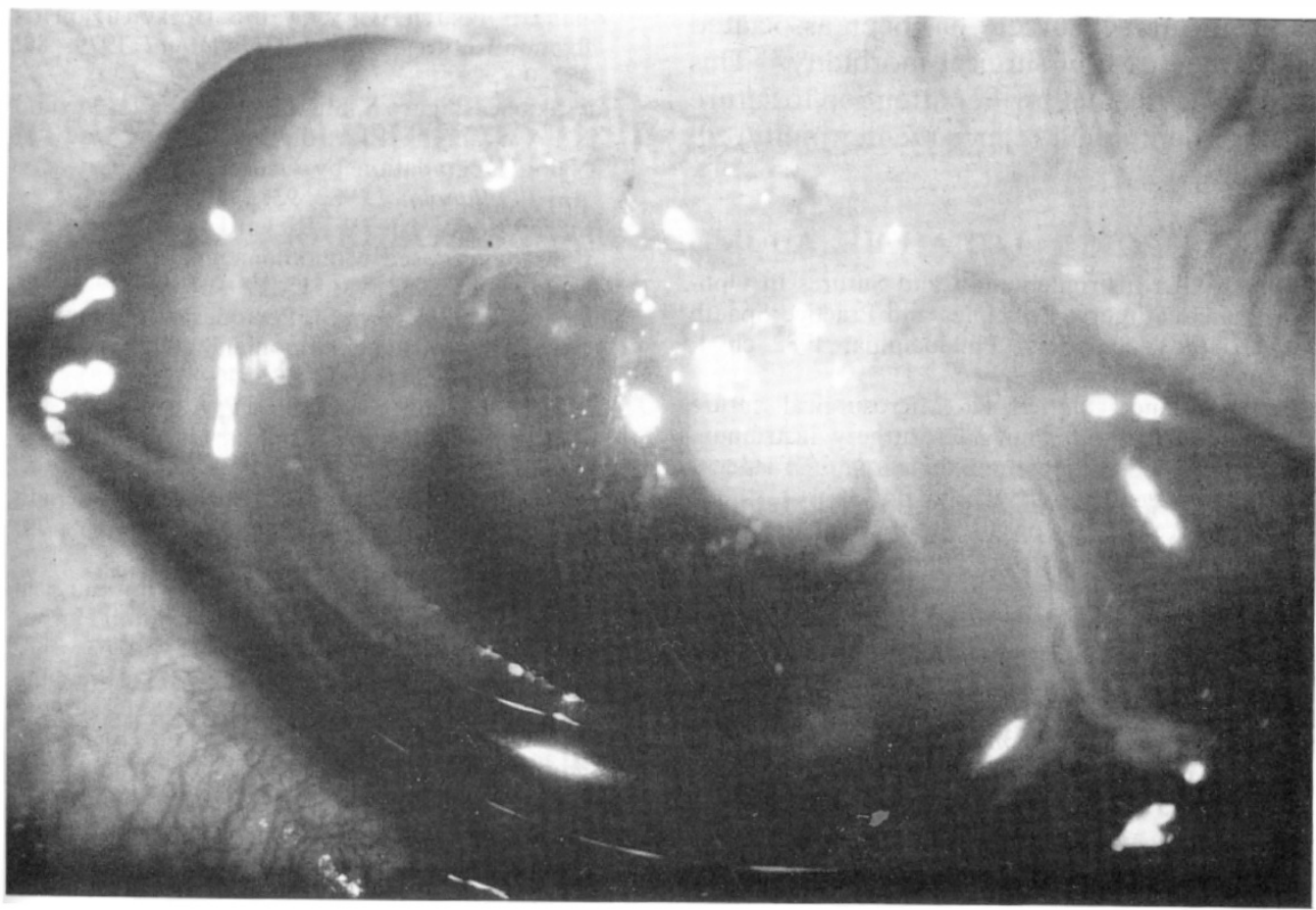

Fig. 7. Suppurative keratitis related to broken nylon suture; this had been removed.

-Elective removal of all nylon sutures 6 to 12 months after surgery, by which time the late cellular phase of avascular stromal healing is complete and animal data indicate that corneal mechanical strength has reached at least $50 \%$ normal. ${ }^{11,12}$ This may prevent all the complications related to loosening and breakage secondary to biodegradation. Furthermore, in our experience removal of sutures at a later stage can be more difficult technically because of further suture decay, resulting in brakage and incomplete removal.

-Corneal sections with nylon sutures may

FORMATION AND HYDROLYSIS OF NYLON 6

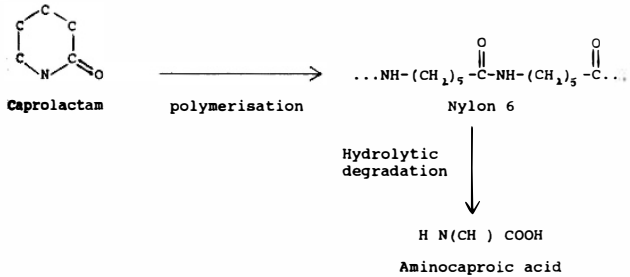

Fig. 8. Formation and hydrolysis of Nylon 6. not be appropriate for cataract extractions on patients in whom suture removal under topical anaesthesia at the slit-lamp would be impractical, for example the very elderly or immobile, patients who may default from follow-up or the mentally retarded. In those patients, a limbal section might be preferred using either 8.0 virgin silk, polyglactin (Vicryl), or a truly non-resorbable suture such as 10.0 polypropylene (Prolene) or polyester (Mersilene).

The widespread adoption of modern microFORMATION AND HYDROLYSIS OF NYLON 6,6 .

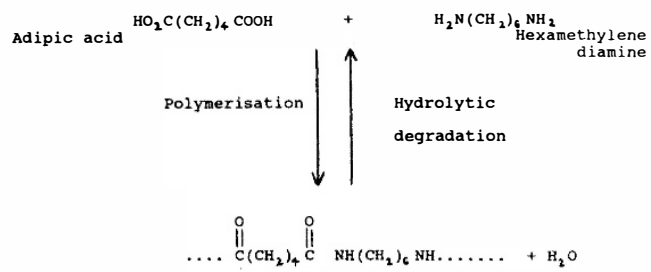

Fig. 9. Formation and hydrolysis of Nylon 6,6. 
surgical cataract surgery has been associated with a decrease in surgical morbidity. ${ }^{13}$ This study suggests that further attention to suture management might reduce the morbidity still further.

\section{References}

${ }^{1}$ Spaeth GL: Instrumentation and Sutures in Ophthalmic Surgery; Principles and Practice Spaeth GL (ed), Saunders, Philadelphia, 1982 ch 4, pp 59-79.

${ }^{2}$ Hutz W and Ullerich K: Microsurgical suture material in Ophthalmic microsurgery; instrumentation, microscopes and technique. Draeger $\mathbf{J}$ (ed), Karger, Basel 1987 ch 8 pp 136-141.

${ }^{3}$ Moore TE and Aronson SB: Suture Reaction in the Human Cornea. Arch Ophthalmol 1969: 82: 575-9.

${ }^{4}$ Balyeat HD, Davis RM, Rowsey J. Nylon Suture Toxicity after Cataract Surgery. Ophthalmology 1988, 95: 1509-14.

${ }^{5}$ Kronenthal RL: Intraocular degradation of nonabsorbable sutures. Am J Intraocular Implant Soc 1977, 3: 222-4.
${ }^{6}$ Cohan BE, Pearch AC, Schwatz S: Broken nylon iris fixation sutures. Am J Ophthalmol 1979, 88: 982-9.

${ }^{7}$ Haysaka S, Ishiguro S, Shiono T, Okabe H, Mizuno K: A Scanning Electron Microscope Study of Nylon Degradation by Ocular Tissue Extracts. Am J Ophthalmol 1982, 93: 111-17.

${ }^{8}$ Nirnkri VS, Karesh JW, Richards RD: Complications of Exposed Monofilament Sutures. Am J Ophthalmol 1983, 95: 515-19.

${ }^{9}$ Shahinian L and Brown SI: Postoperative complications with protruding monofilament nylon suture: Am J Ophthalmol 1977, 83: 546-8.

${ }^{10}$ Blanksma LJ and Siertsema JV: Changes in the structure of intra-ocular nylon. Doc Ophthalmol 1977, 44: 223-9.

${ }^{11}$ Gasset AR and Dohlman CH: The Tensile Strength of Corneal Wounds. Arch Ophthalmol 1968, 79: 595-602.

${ }^{12}$ Yanoff $\mathbf{M}$ and Fine BS: Surgical and Non-Surgical Trauma; in Ocular Pathology 2nd Edition Harper \& Row, Philadelphia, 1982: pp 132-138.

${ }^{13}$ Acheson JF, McHugh JD, Falcon MG: Changing patterns of early complications in cataract surgery with new techniques: a surgical audit. $\mathrm{Br} J \mathrm{Oph}$ thalmol 1988: 72: 481-4. 